\title{
Modification of speed and current limiting performance of BLDC motor based on harmony search optimization method
}

\author{
Mohammed Qasim Abbas, Yaser Atta Yassin \\ Department of Electrical Power Engineering Techniques, Middle Technical University, Iraq
}

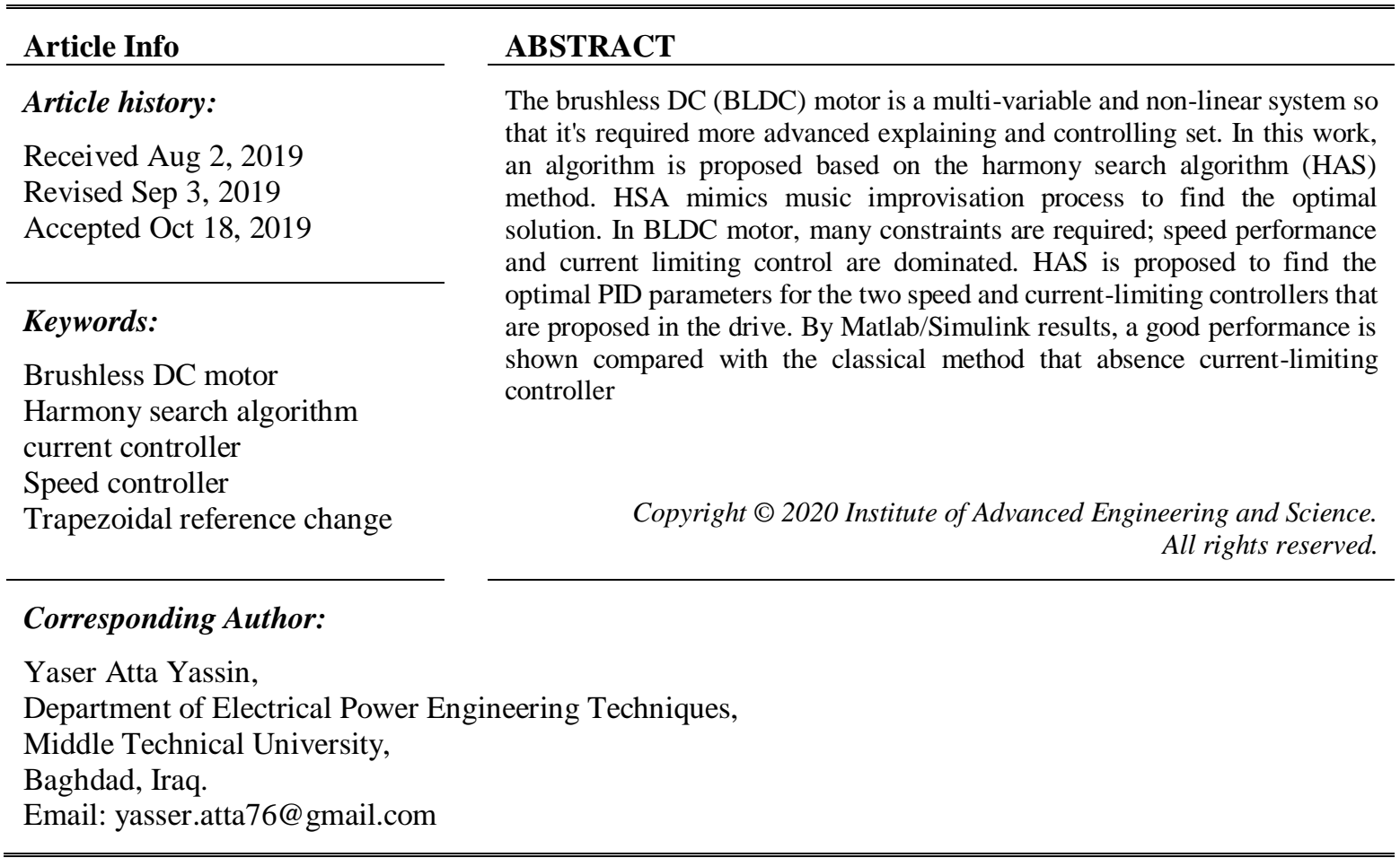

\section{INTRODUCTION}

Rapid increasing and most requests have to tend for the applications of BLDC motor started from household applications tends to industrial and aerospace services. As all the BLDC motor applications are due to its advantages such as its high dynamic response, wide speed range, high efficiency of operation and noiseless $[1,2]$.

BLDC motor is similar to the synchronous motor with the permanent magnet. Electronic switches inverter is used for current commutation. The inverter is supplied from dc supply that the name came. The rotor position, detected either by hall sensor or any other method, is necessary for deriving the inverter to supply the three-phase trapezoidal stator windings. No need to model the damper winding and the rotor is lapsed because of high resistivity of the stainless-steel magnet [3]. To make synchronous between back emf's and stator currents, the last have to be quasi-square shape to produce high torque and steady speed. The six-step strategy is the known operation for stator that makes two phases on and the third is float [4-6].

Different speed control techniques are proposed and implemented to achieve an accurate torque rate and speed control behavior. The control used in most research depends on the PID controller in which its parameters are tuned either by trial and error, Ziegler-Nicholas, a fuzzy optimization technique, genetic or particle swarm optimization [5-7]. Advanced techniques to improve the operation of the PID controller are also interested such as employing fractional-order PID-Controller and using this controller via two order of freedom [8-10]. Some researchers have expanded the structure of Artificial intelligence to control the nonlinear system such as wavelet and wavelet neural network (Wave net) approaches [11-14].

Speed and current limiting strategy make a necessary role in modern control for BLDC motor drive. This paper proposes a pulse width modulation (PWM) system for BLDC motor to control the speed and limit the current during starting and operating conditions using two PID controllers. Each PID controller parameters 
are tuned using the proposed harmony search optimization technique. The MATLAB software program is used to show the complete system processes. The BLDC motor performance in terms of speed control and modification of current are tested and the results are discussed.

\section{EQUIVALENT CIRCUIT AND MODELING OF BLDC MOTOR}

As the stator of synchronous motor, the stator of BLDC motor appears. It has a three-phase winding in the stator while the rotor consists of permanent magnets. A style of BLDC motor supplied from the threephase inverter is shown in Figure1. The ultimate voltage frontier of the stator must be bigger than the peak voltage and is to be lower than motor back emf [15].

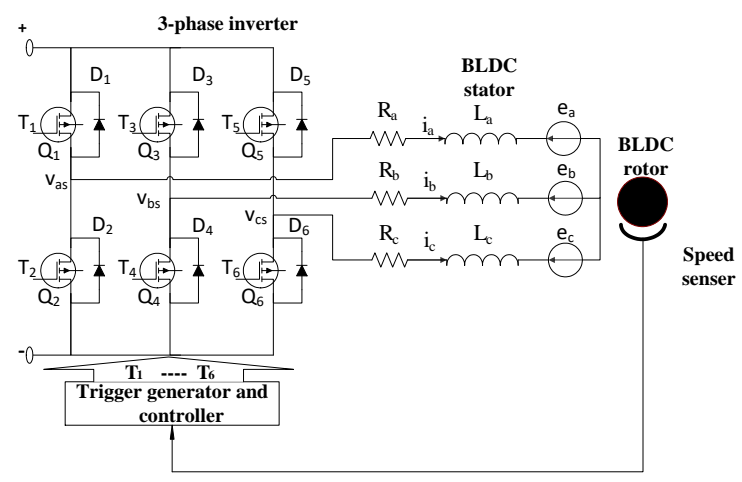

Figure 1. The BLDC motor represented by its equivalent circuit

The 3-phase voltages for the motor connected to its inverter can be given as follows:

$$
\left[\begin{array}{c}
\mathrm{v}_{\mathrm{as}} \\
\mathrm{v}_{\mathrm{bs}} \\
\mathrm{v}_{\mathrm{cs}}
\end{array}\right]=\left[\begin{array}{ccc}
\mathrm{R} & 0 & 0 \\
0 & \mathrm{R} & 0 \\
0 & 0 & \mathrm{R}
\end{array}\right]\left[\begin{array}{c}
\mathrm{i}_{\mathrm{a}} \\
\mathrm{i}_{\mathrm{b}} \\
\mathrm{i}_{\mathrm{c}}
\end{array}\right]+\left[\begin{array}{ccc}
\mathrm{L}-\mathrm{M} & 0 & 0 \\
0 & \mathrm{~L}-\mathrm{M} & 0 \\
0 & 0 & \mathrm{~L}-\mathrm{M}
\end{array}\right] \frac{\mathrm{d}}{\mathrm{dt}}\left[\begin{array}{c}
\mathrm{i}_{\mathrm{a}} \\
\mathrm{i}_{\mathrm{b}} \\
\mathrm{i}_{\mathrm{c}}
\end{array}\right]+\left[\begin{array}{c}
\mathrm{e}_{\mathrm{a}} \\
\mathrm{e}_{\mathrm{b}} \\
\mathrm{e}_{\mathrm{c}}
\end{array}\right]
$$

where $\mathrm{v}_{\mathrm{as}}, \mathrm{v}_{\mathrm{bs}}$ and $\mathrm{v}_{\mathrm{cs}}$ are the motor stator voltages; $\mathrm{R}$ is the stator phase resistance; $\mathrm{i}_{\mathrm{a}}, \mathrm{i}_{\mathrm{b}}$ and $\mathrm{i}_{\mathrm{c}}$ are the stator phase currents and $\mathrm{e}_{\mathrm{a}}, \mathrm{e}_{\mathrm{b}}$ and $\mathrm{e}_{\mathrm{c}}$ are the stator back emf's phase voltage.

The above phase voltages equations can be extracted in terms of the line voltage equations as $[2,15]$ :

$$
\left[\begin{array}{c}
v_{a b} \\
v_{b c} \\
v_{c a}
\end{array}\right]=\left[\begin{array}{ccc}
R & -R & 0 \\
0 & R & -R \\
-R & 0 & R
\end{array}\right]\left[\begin{array}{c}
i_{a} \\
i_{b} \\
i_{c}
\end{array}\right]+\left[\begin{array}{ccc}
L-M & M-L & 0 \\
0 & L-M & M-L \\
M-L & 0 & L-M
\end{array}\right] \frac{d}{d t}\left[\begin{array}{c}
i_{a} \\
i_{b} \\
i_{c}
\end{array}\right]+\left[\begin{array}{c}
e_{a}-e_{b} \\
e_{b}-e_{c} \\
e_{c}-e_{a}
\end{array}\right]
$$

with considering a balance 3-phase source and 3-phase stator winding, two equations can be extracted due to:

$$
\mathrm{i}_{\mathrm{a}}+\mathrm{i}_{\mathrm{b}}+\mathrm{i}_{\mathrm{c}}=0
$$

These two equations are given in terms of phase $a$ and $b$ as follows:

$$
\begin{aligned}
& \frac{d}{d t} i_{a}=-\frac{R}{L-M} i_{a}+\frac{2}{3(L-M)}\left(v_{a b}-e_{a b}\right)+\frac{1}{3(L-M)}\left(v_{b c}-e_{b c}\right) \\
& \frac{d}{d t} i_{b}=-\frac{R}{L-M} i_{b}-\frac{1}{3(L-M)}\left(v_{a b}-e_{a b}\right)+\frac{1}{3(L-M)}\left(v_{b c}-e_{b c}\right)
\end{aligned}
$$

The back emf's in BLDC motor has a trapezoidal shape depend on rotor position, which is phaseshifted by 120 degree. These back emf's equations can be expressed as $[2,15]$ :

$$
\begin{aligned}
& e_{a}=\frac{k_{e}}{2} w_{m} F\left(\theta_{e}\right) \\
& e_{b}=\frac{k_{e}}{2} w_{m} F\left(\theta_{e}-\frac{2 \pi}{3}\right)
\end{aligned}
$$




$$
\mathrm{e}_{\mathrm{c}}=\frac{\mathrm{k}_{\mathrm{e}}}{2} \mathrm{w}_{\mathrm{m}} \mathrm{F}\left(\theta_{\mathrm{e}}+\frac{2 \pi}{3}\right)
$$

where $\mathrm{k}_{\mathrm{e}}$ is the constant of back-emf; $\mathrm{w}_{\mathrm{m}}$ is the motor speed and $\theta_{\mathrm{e}}$ is the rotor angle (electrical), as:

$$
\theta_{\mathrm{e}}=\frac{\mathrm{p}}{2} \theta_{\mathrm{m}}
$$

P: number of the poles and $\theta_{\mathrm{m}}$ is the rotor mechanical angle, as:

$$
\theta_{\mathrm{m}}=\int_{0}^{\mathrm{t}} \mathrm{w}_{\mathrm{m}} \mathrm{dt}
$$

The function $\mathrm{F}\left(\theta_{\mathrm{e}}\right)$ represents the trapezoid back emf's, for one cycle as:

$$
\mathrm{F}\left(\theta_{\mathrm{e}}\right)=\left\{\begin{array}{c}
10 \leq \theta_{\mathrm{e}}<\frac{2 \pi}{3} \\
1-\frac{6}{\pi}\left(\theta_{\mathrm{e}}-\frac{2 \pi}{3}\right) \frac{2 \pi}{3} \leq \theta_{\mathrm{e}}<\pi \\
-1 \pi \leq \theta_{\mathrm{e}}<\frac{5 \pi}{3} \\
-1+\frac{6}{\pi}\left(\theta_{\mathrm{e}}-\frac{5 \pi}{3}\right) \frac{5 \pi}{3} \leq \theta_{\mathrm{e}}<2 \pi
\end{array}\right.
$$

The torque in the rotor generates power as [17]:

$$
\begin{aligned}
& \mathrm{p}_{\mathrm{e}}=\mathrm{e}_{\mathrm{a}} \mathrm{i}_{\mathrm{a}}+\mathrm{e}_{\mathrm{b}} \mathrm{i}_{\mathrm{b}}+\mathrm{e}_{\mathrm{c}} \mathrm{i}_{\mathrm{c}} \\
& \mathrm{p}_{\mathrm{e}}=\mathrm{T}_{\mathrm{e}} \mathrm{w}_{\mathrm{m}}
\end{aligned}
$$

where $\mathrm{T}_{\mathrm{e}}$ is the developed torque which can be from equations $(6-8,12$ and 13) as follows:

$$
\mathrm{T}_{\mathrm{e}}=\frac{\mathrm{k}_{\mathrm{t}}}{2}\left[\mathrm{~F}\left(\theta_{\mathrm{e}}\right) \mathrm{i}_{\mathrm{a}}+\mathrm{F}\left(\theta_{\mathrm{e}}-\frac{2 \pi}{3}\right) \mathrm{i}_{\mathrm{b}}+\mathrm{F}\left(\theta_{\mathrm{e}}+\frac{2 \pi}{3}\right) \mathrm{i}_{\mathrm{c}}\right]
$$

Generally, the motion equation includes:

$$
\mathrm{T}_{\mathrm{e}}-\mathrm{T}_{\mathrm{L}}=\mathrm{J} \frac{\mathrm{dw_{m }}}{\mathrm{dt}}+\mathrm{k}_{\mathrm{f}} \mathrm{W}_{\mathrm{m}}
$$

where $\mathrm{T}_{\mathrm{L}}$ is the load torque, $\mathrm{k}_{\mathrm{t}}$ is $\mathrm{T}_{\mathrm{e}}$ constant, $\mathrm{k}_{\mathrm{f}}$ is constant for viscous friction and $\mathrm{J}$ is the inertia for the rotor.

\section{ROTOR SPEED AND LIMITING LINE CURRENT CONTROL IN BLDC MOTOR DRIVE}

As a comparing among the motor types, the motor of the BLDC motor has more problematic control strategy. The well-known methods of controlling a BLDC motor are three: control by hysteresis band, also controlled by a variable DC-Link voltage and finally control by PWM for the switching signals [15]. Typically, the common control system is a closed dual-loop. The interior loop is responsible for the torque adjustment as well the current to the proper value, whilst the other circuit is the outer speed circuit, that's hired to control the speed of the motor. Figure 2 shows the graphical diagram of the drive for the BLDC motor. Subtract the reference speed by rotor speed to produce the speed error signal which is fed to a speed controller that its result is confined by the upper reference current.

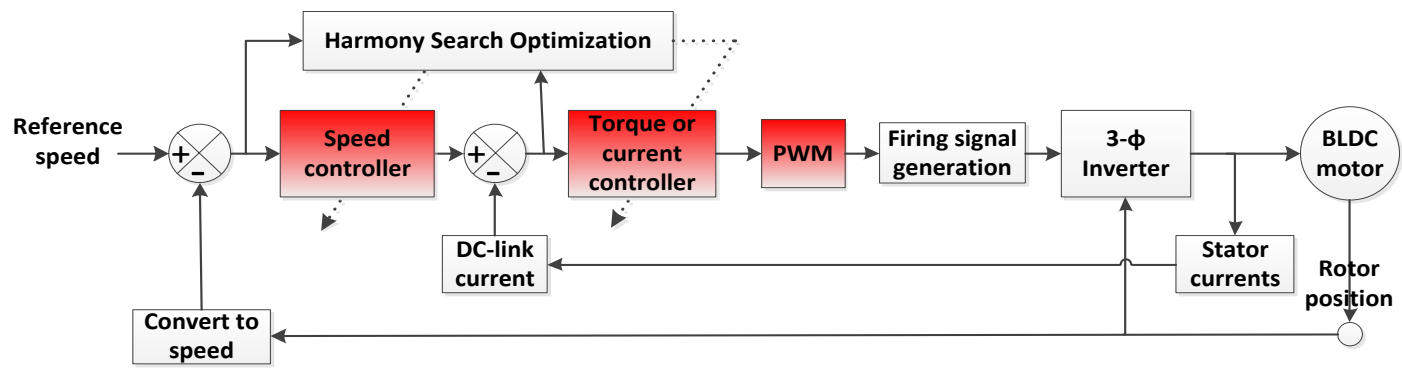

Figure 2. Graphical diagram of the drive for BLDC motor PWM control system of the speed 
A reference current value is derived from the following reference torque relationship [2]:

$$
\mathrm{I}_{\mathrm{ref}}=\frac{\mathrm{T}_{\mathrm{ref}}}{\mathrm{k}_{\mathrm{t}}}
$$

The current of DC-link equivalent signal is synthesized of the 3-phase stator's currents thereafter subtracted of the output of a speed controller. Thereafter, the signal of error is fed directly to a controller of a torque. Here the output controller of torque is fed directly to the form of PWM to compare it through a triangular waveform as the comparative output is a low signal or a high signal that turns as the chopping signal into the inverter as appeared in Figure 4. The speed of BLDC motor immediately alterations by a duty cycle modulation of the firing signals inverter switches leans on the error signal of the controller. In this method of control, the motor will switch on and off through a high average, the frequency of chopping is steady but the error of control will change the length of a duty cycle [2]. The actuality of the constant frequency lets the acoustic filtering and electromagnetic noise easier. The frequency of switching is usually taking (20-50) $\mathrm{kHz}$ where the maximum frequency of switching will give a smoother torque as a result of a low distinction in the current. The control system suggestion is consists of suggested sensors of currents to apply a requisite 3-phase currents to snaffle a current of DC-Link. This is advantageous for staying the current of a motor at the coveted value through the starting and during the speed step variation by existence the controller of a torque. By this way, the signals of firing are controlled the length of the duty cycle for a PWM; speed controlling is obtaining.

\section{HARMONY SEARCH OPTIMIZATION METHOD}

Harmony search (HS) is a phenomenon-mimicking metaheuristic algorithm which has been proposed in [16]. HS is a novel approach inspired by the musical operation of searching an ideal case of harmony as in music improvisation where the pitch of each musical instrument is improved to accomplish this better state of harmony. The pitch determines the quality of music, just as the fitness function value determines the quality of solutions. Furthermore, the improvisations of musician are analogous to native and global seek sketch in optimization strategies. HS has been used to solve various types of optimization problems [17]. It is showing significant improvements over other heuristics. A lot of modified HS algorithms have been studied to enhance the performance of the original version [18].

\subsection{Technique of Optimization}

The Techniques of optimization are broadly classified into deterministic techniques of optimization and heuristic techniques of optimization. In this paper, it has implemented the Harmony Search Algorithm (HSA) as a technique of optimization because it's an efficient and effective inspired algorithm from nature. Executive steps of that HSA have been shown in Figure 3. HSA was suggested by Zong Wo Geem et al., [16] in 2001. Seeking for better and new harmony it's called improvisation of harmony. Process of improvisation accomplishes in a band of musical where any musician has several tools to play. Any band from the musician can be seen as a solution space decision variable. Every tool has several pitch zones which depicts decision variables range [16]. The musical band particular iteration, at a set time through the process of improvisation, leads to the musical harmony that is afterward the Harmony Memory (HM) is updated. HM is the structure of a core data utilized in HSA and it has best solution matrix vectors. HM size describes vectors processed counts with each other. The parameters of HSA are selected manually which are shown in Table 1 of this paper for an optimal solution of the PID parameters.

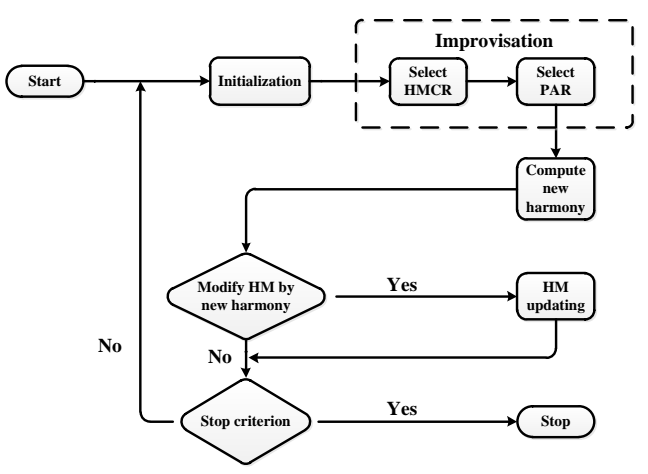

Table 1. HSA Parameters

\begin{tabular}{lc}
\hline Parameter & Value \\
\hline Number of PID variables & 5 \\
Maximum iterations & 100 \\
HMCR & 0.9 \\
PAR & 0.98 \\
HMS & 50 \\
Number of New Harmonies & 20 \\
FW & $0.2 *(\mathrm{U}-\mathrm{L})$ \\
FW $_{\text {damp }}$ & 0.955 \\
\hline
\end{tabular}

Figure 3. Procedural steps of HSA

Indonesian J Elec Eng \& Comp Sci, Vol. 18, No. 1, April 2020 : 549 - 557 


\subsection{HSA Executive Steps}

The HS algorithm has five executive steps viz: process initialization, initiation of harmony memory, improvisation of unprecedented harmony, HM updating and test a stop criterion. All these proceedings are briefly qualified below [19]:

a) Process of initialization:

Define the lower and upper limit of PID variables $x_{i}^{L} \leq x_{i} \leq x_{i}^{U}$, where $x i$ is any gain of the PID parameters, $\mathrm{L}$ and $\mathrm{U}$ is the lower and upper limit respectively of these parameters. Harmony Memory Size (HMS) value decision, Harmony Memory Consideration Rate (HMCR) value decision, Pitch Adjustment Rate (PAR) value decision, Fret Width (Bandwidth) (FW), Fret Width Damp Ratio (FWdamp) and Define maximum iterations

b) Initiation of the HM: HM matrix is generated randomly for HMS out of the following equation.

$$
\mathrm{x}_{(\mathrm{i}, \mathrm{j})}=\mathrm{l}_{\mathrm{j}}+\operatorname{rand}() \cdot \mathrm{U}_{\mathrm{j}}+\mathrm{l}_{\mathrm{j}}
$$

where $\mathrm{x}(\mathrm{i}, \mathrm{j})$ shows initial HM jth element. Rand ( ) function produces random values amidst 0 and 1 whereas $\mathrm{lj}$ and $\mathrm{Uj}$ are lower and upper bound respectively.

c) New harmony process of improvisation: a process of Improvisation for the new harmony is started by step 3 of HSA. This process consists of three sub-steps: HMCR, random selection and PAR. generate a number randomly between 0 and 1 with the help of the rand ( ). Insomuch as the randomly produced value is minimal than $\mathrm{HM}$ consideration rate thereafter the value is chosen of that particular position. Insomuch as a random number is maximal than HMCR thereafter generate a new random number.

This process will appear in the equation below:

$$
V_{i, j}=\left\{\begin{array}{c}
x(\operatorname{randj}) \text { if } \operatorname{randb}() \text { is }<\text { HMCR } \\
l_{j}+\operatorname{rand}() . U_{j}-l_{j} \text { else }
\end{array}\right.
$$

The elements of memory are selected from the HMCR step, are further amended with PAR. The PAR equation has appeared in the below.

$$
V_{i, j}=\left\{\begin{array}{c}
V_{i}^{j} \operatorname{rand}() \cdot \text { bwj if rand ( ) is }<\text { PAR } \\
V_{i}^{j} \text { else }
\end{array}\right.
$$

d) HM update: when new process of harmony improvisation completes then updates a new harmony in the HM worst among already present HMs is removed from HM.

e) 5) Checking the criteria of stopping: when improvisation process arrives at its iterations maximum number or halting criteria of Integrate Time Absolute Error (ITAE) of the multi-objective function as shown in equation (20) below, then calculation process of HSA cut out. Otherwise, the process repeats from step 3 and step 4.

$$
\mathrm{F}=\int \mathrm{t} *\left|\mathrm{e}_{\mathrm{s}}\right| \mathrm{dt}+\int \mathrm{t} *\left|\mathrm{e}_{\mathrm{i}}\right| \mathrm{dt}
$$

where $e_{s}$ is the speed error and $e_{i}$ is the current error.

\section{PROPOSED SIMULINK MODEL FOR BLDC MOTOR BASED ON HAS TECHNIQUE}

The set of equations (1-15) are used to be modeled by the software of Matlab/Simulink (R2015a) at Bogaki-Shampine (ode3) with the solver of the fixed step kind by primary sample time is $3.125 * 10^{-6}$ seconds to perform BLDC motor supplied from a 3-phase inverter. This model is shown in Figure 4. The BLDC motor used in this work has the specifications given in Table 2.

The proposed Simulink model for BLDC motor including the dual loops is shown in Figure 5. According to the schematic diagram given in Figure 2, each control loop includes a PID controller. The parameters of these controllers are optimized by the HS method. The outer loop controls the motor speed while the inner loop controls and limits the line current to a value that remains the motor in safety operation condition. The objective function given in equation 20 is represented in Simulink as shown in Figure 6. The optimized parameters for PID controllers are given in Table 3. 
Table 2. BLDC motor specifications

\begin{tabular}{lcc}
\hline Type of parameter & value & Unit \\
\hline Output power & 1200 & $\mathrm{~W}$ \\
Line current & 16 & $\mathrm{~A}$ \\
Terminal voltage & 76 & $\mathrm{~V}$ \\
Full load torque & 2.9 & $\mathrm{~N} . \mathrm{m}$ \\
Current at no load & 0.66 & $\mathrm{~A}$ \\
The speed at no load & 3500 & $\mathrm{Rpm}$ \\
Motor torque constant & 0.207 & $\mathrm{Nm} / \mathrm{A}$ \\
The resistance between two & 0.110 & $\Omega$ \\
terminals & 0.207 & $\mathrm{~V} . \mathrm{s} / \mathrm{rad}$ \\
Motor voltage constant & 0.6 & $\mathrm{mH}$ \\
L-M inductance & $1.7 \times 110^{-3}$ & $\mathrm{~kg} . \mathrm{m}^{2}$ \\
Rotor inertia & $1.3 \times 10^{-4}$ & $\mathrm{~N} . \mathrm{m} \mathrm{s} / \mathrm{rad}$ \\
Motor viscous damping factor & 8 & \\
Poles number & &
\end{tabular}

Table 3. Optimized parameters of PID

\begin{tabular}{lc}
\hline Parameters & Values \\
\hline \multicolumn{2}{c}{ Motor speed controller } \\
Proportional $\left(\mathrm{k}_{\mathrm{p}}\right)$ & 13.940 \\
Integral $\left(\mathrm{k}_{\mathrm{i}}\right)$ & 0.1268 \\
Derivative $\left(\mathrm{k}_{\mathrm{d}}\right)$ & 0.02022 \\
\multicolumn{2}{c}{ Current controller } \\
Proportional $\left(\mathrm{k}_{\mathrm{p}}\right)$ & 9.829 \\
Integral $\left(\mathrm{k}_{\mathrm{i}}\right)$ & 6.599 \\
\hline
\end{tabular}

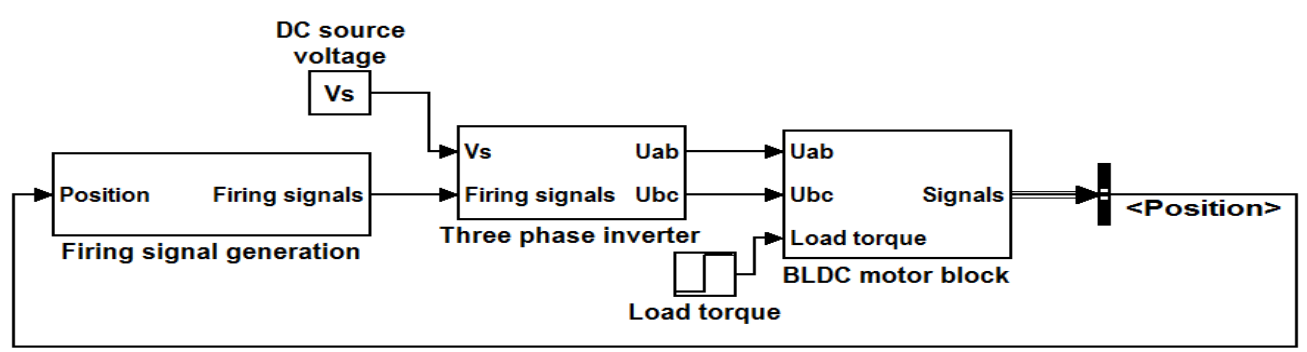

Figure 4. BLDC motor controlled by 3-phase inverter Simulink model

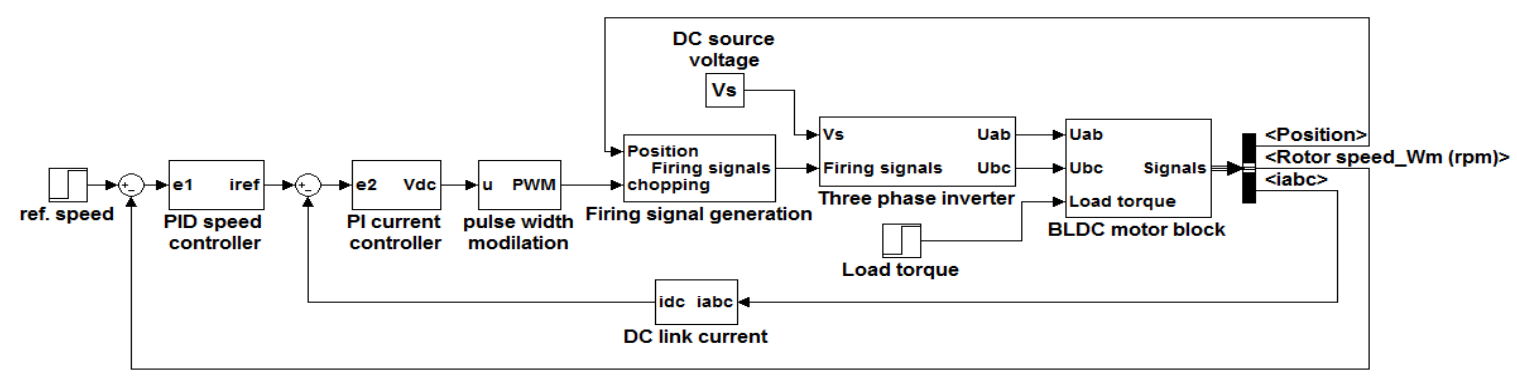

Figure 5. Proposed dual control loops for BLDC motor Simulink model

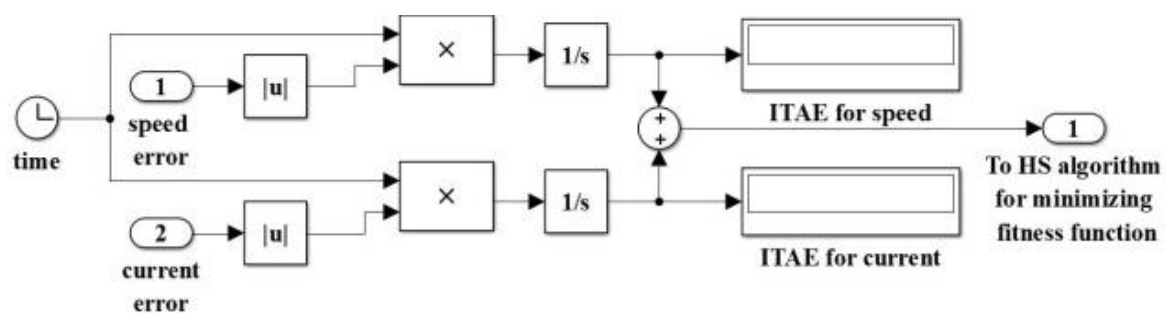

Figure 6. Multi-objective function block diagram

\section{SIMULATION AND RESULTS}

The simulation results show that the PID speed and current controllers' gains are shown in Table 3 which obtained from HSA during run the system with its parameters shown in Table 1.

Figures (7-9) shows the speed response, stator current for phase (a) and developed torque respectively for the BLDC motor drive system with and without current controller by starting with $2000 \mathrm{rpm}$ reference speed and applying 2.9 N.m at 0.5 second during 1 second simulation time. The performance of the BLDC motor by changing the reference speed by trapezoidal input and starting directly with a full load is shown in 
Figure 10 fore speed response and Figures (11 and 12) for developed torque and current respectively surely with the current controller. These results ensure the validity of the model, the speed, current and torque reach to its new values quickly.

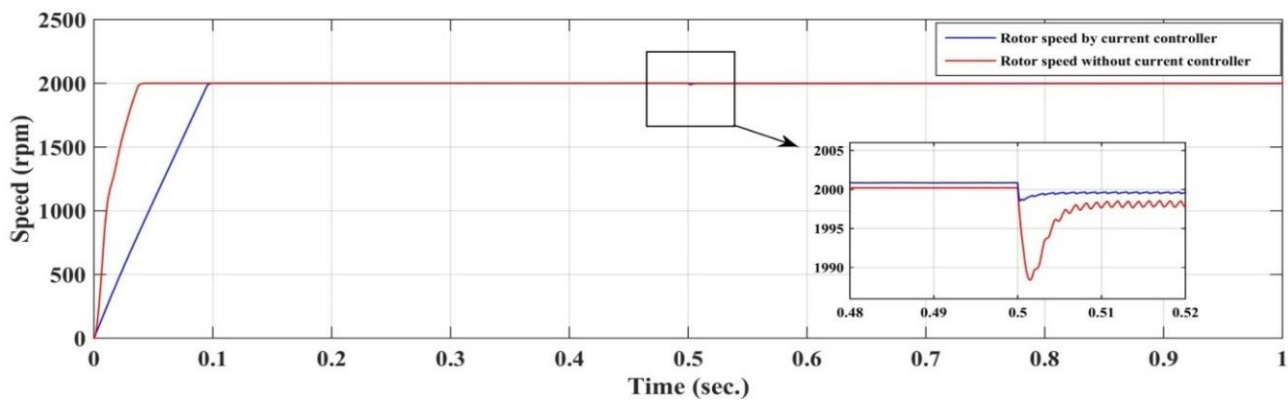

Figure 7. Speed response with and without a current controller

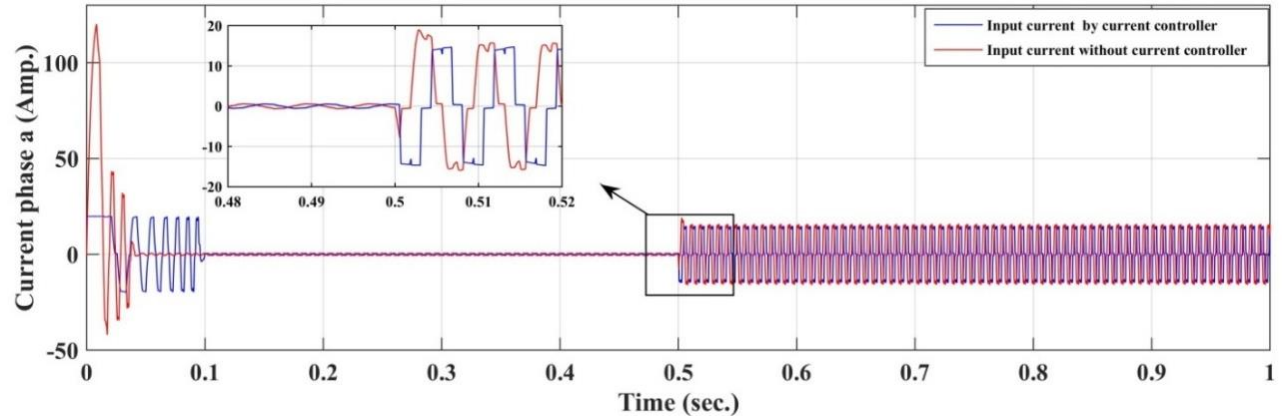

Figure 8. The current phase (a) with and without a current controller

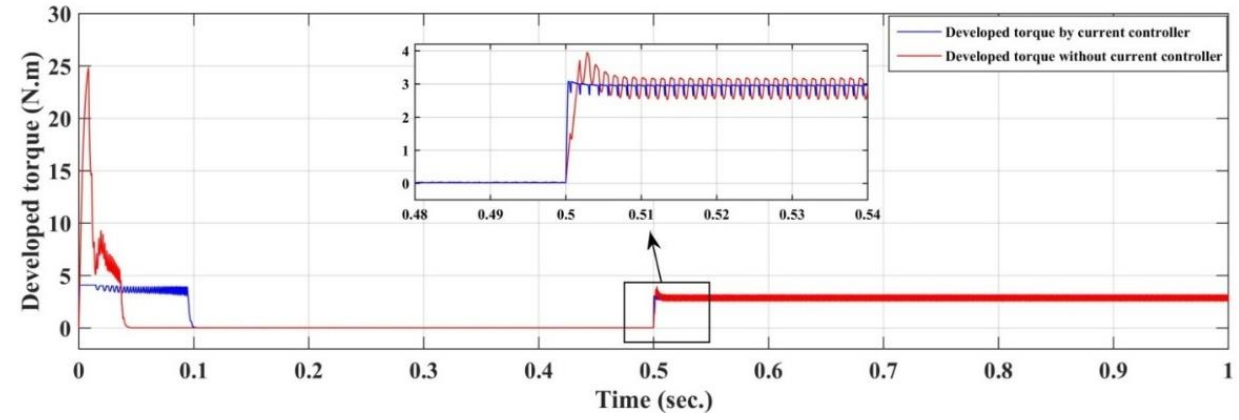

Figure 9. Developed torque with and without a current controller

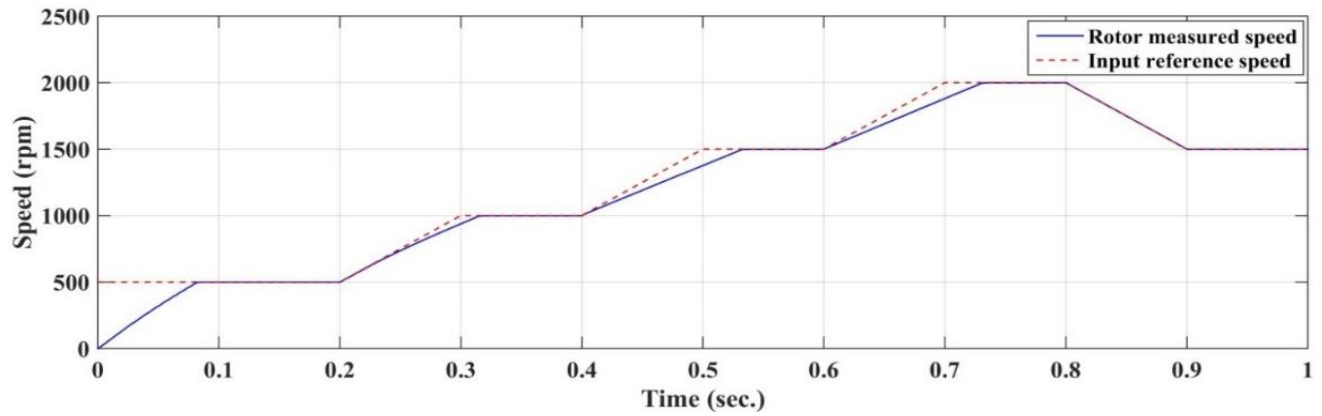

Figure 10. Speed response by trapezoidal reference speed. 


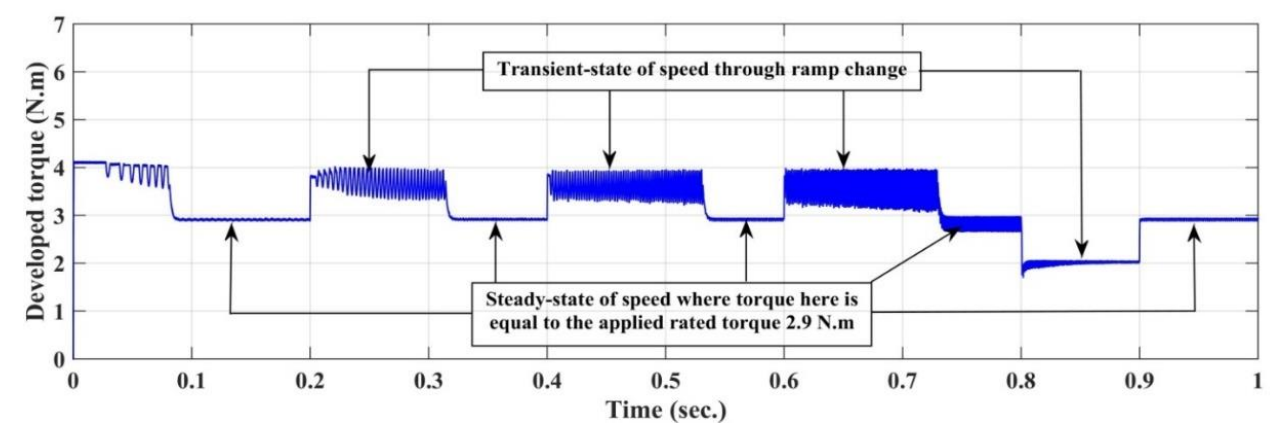

Figure 11. Developed torque response by trapezoidal reference speed

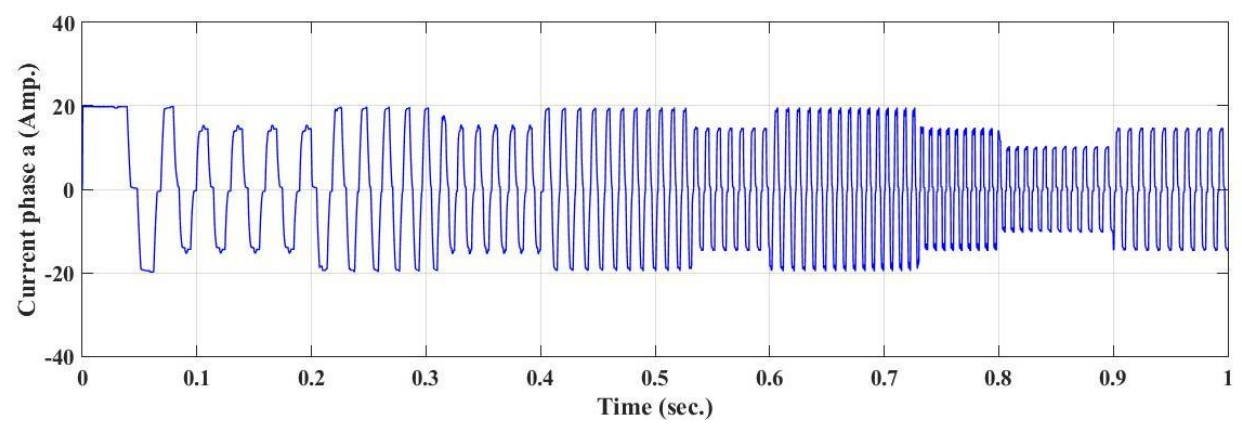

Figure 12. Current response by trapezoidal reference speed

\section{COMPARISON BETWEEN CONTROLLING METHODS}

The comparison is done concerning to the operation and results from the output waveform of the performing models as shown in Table 4. The proposed controlling method has a complex hardware structure but it gives a better load rejection. And the $2^{\text {nd }}$ current loop will dissipate small power through the CT's of the currents measurement.

Table 4. Comparison between controlling methods

\begin{tabular}{lcc}
\hline Feature & Without current controller & With current controller \\
\hline Rise time & Faster & Slower \\
Starting and running response & Good & Better \\
Ripple & High & Low \\
Accuracy & Less & More \\
Investment cost & Small & Higher because of the 2 $2^{\text {nd }}$ loop \\
\hline
\end{tabular}

\section{CONCLUSION}

The current controller was setting the current and overcome the high starting current. In this paper, the PID parameters were obtained using HSA it's found is easier and faster to get the result than other used optimized technique. This is used to control the BLDC motor speed and current also can provide better performance of the motor variables. The benefit of the using HSA is to reach a better response of the speed, overcoming the load rejection and good robustness system during trapezoidal reference speed change at direct starting load. The results of different BLDC motor variables are plotted, discussed and compared. The current controller has more rising time in speed but good load rejection and less oscillation. The result of current and torque shows the more ripple in the ramp change of the speed but this disadvantage can overcome by re-running the optimization algorithm in this state.

\section{REFERENCES}

[1] Chang-liang Xia, "Permanent magnet brushless DC motor drives and controls," John Wiley \& Sons, First Edition, ISBN 978-1-118-18833-0, 2012. 
[2] Stefan B., "BLDC motor modeling and control a Matlab/Simulink implementation", Master Thesis in Electrical Power Engineering, Chalmers University of Technology, Gothenburg, Sweden, May 2005.

[3] Shivraj S. Dudhe and Archana G. Thosar, "Mathematical modeling and simulation of three phase BLDC motor using Matlab/Simulink", International Journal of Advances in Engineering \& Technology, 7(5), pp.1426-1433, 2014.

[4] H. Hao, JianxinShen, Cheng Yuan, and QiangQu, "Influences of machine structure on high speed PM BLDC motor", Electrical Machines and Systems (ICEMS), 17th International Conference on IEEE, 2014.

[5] Mikerov, Alexander G. "Brushless DC torque motors quality level indexes for servo drive applications", EUROCON'09, IEEE, 2009.

[6] Kerdsup, Burin, and Nisai H. Fuengwarodsakul, "Analysis of brushless DC motor in operation with magnetic saturation using FE method", Electrical Engineering/Electronics, Computer, Telecommunica-tionsand Information Technology (ECTI-CON), 8th International Conference on IEEE, 2011.

[7] Zhang, Songmao, and Yunliang Wang. "The simulation of BLDC motor speed control based-optimized fuzzy PID algorithm", Mechatronics and Automation (ICMA), International Conference on IEEE, 2016.

[8] Adel A.Obed and Ameer L. Saleh, "Speed Control of Brushless DC Motor based on Fractional Order PID Controller", International Journal of Computer Applications 95.4, 2014.

[9] P. Vimala, C. R. Balamurugan, A. Subramanian and T. Vishwanath, "Optimization and comparative analysis of pid and fopid controller for bldc motor," IAES International Journal of Robotics and Automation (IJRA), Vol 8, No 2: June 2019.

[10] Kadhim, Abbas K., and Adel A. Obed. "Brushless DC Motor Speed Control Based on PID Controller with 2-DOF and Anti-Windup Techniques."The Second Engineering Conference for Graduate Research, Middle Technical University-Electrical Engineering Technical College Baghdad-Iraq, SECGR 01-01, 2017.

[11] Adel A. Obed and Ameer L. Saleh. "Speed control of BLDC motor based on recurrent wavelet neural network". Iraq J. Electrical and Electronic Engineering, Vol.10, No.2, pp.118-129, 2014.

[12] Adel A. Obed, Ameer L. Saleh and Abbas K. Kadhim, "Speed performance evaluation of BLDC motor based on dynamic wavelet neural network and PSO algorithm, "International Journal of Power Electronics and Drive System (IJPEDS), Vol. 10, No. 4, 2019.

[13] Muhammed A. Ibrahim, Ausama Kh. Mahmood and Nashwan Saleh Sultan, "Optimal PID controller of a brushless dc motor using genetic algorithm, "International Journal of Power Electronics and Drive Systems (IJPEDS), Vol 10, No 2: June 2019.

[14] Adel A. Obed and Abbas K. Kadhim, "Multi-Resolution Wavelet PID Speed and Current Controllers of BLDC Motor Based on Invasive Weed Optimization Technique", International Journal of Applied Engineering Research, ISSN 0973-4562 Vol.13, No. 8, pp. 6234-6243, Apr 2018.

[15] Adel A. Obed and Abbas K. Kadhim, "Speed and Current Limiting Control Strategies for BLDC Motor Drive System: A Comparative Study" International Journal of Advanced Engineering Research and Science (IJAERS), ISSN: 2456-1908(O), Vol-5, Issue-2, pp. 119-130, Feb- 2018.

[16] Z. W. Geem, J. H. Kim. V. Loganathan, "A new huristic optimization algorithm: harmony search," Simulation, Vol. 76, No. 2, pp. 60-68, 2001.

[17] Rose M. Al Qasem, and Samah M. Massadeh. "Solving Cell Placement Problem Using Harmony Search Algorithms." Engineering, Technology \& Applied Science Research, Vol.8, No.4, p.p. 3172-3176, 2018.

[18] Q. K. Pan, P. N. Suganthan, J. J. Liang, M. F. Tasgetiren, "A local-best harmony search algorithm with dynamic subpopulations”, Engineering Optimization, Vol. 42, No. 2, pp. 101-117, 2010.

[19] Syed Muhammad Mohsin, Nadeem Javaid, Sajjad Ahmad Madani, Syed Kashif Abbas, Syed Muhammad Abrar Akber \& Zahoor Ali Khan. "Appliance Scheduling in Smart Homes with Harmony Search Algorithm for different Operation Time Intervals". In 2018 32nd International Conference on Advanced Information Networking and Applications Workshops IEEE. (WAINA), pp. 51-60, May-2018.

\section{BIOGRAPHIES OF AUTHORS}

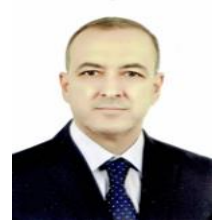

Mohammed Qasim Abbas recived his B.Sc from Univerity of Technology / Iraq. 1990 from Electrical and Electronic Engineering Department, M.Sc from University of Technology / Iraq. 1996 in Power Engineering. He is currently Assist Lecturer in Dept. of Electrical Power Technical Engineering / Electrical Engineering Technical College / Middle Technical University (phone: +9647901478977, email: Mohammad.Qassem@eetc.mtu.edu.iq).

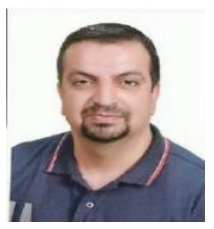

Yaser Atta Yassin recived his B. Sc from Al Mustansiriyah University / Iraq 1999 from College of Engineering-Department of Electrical Engineering. M.Sc from National Research University/Moscow Power Engineering Institute/Russia/2017. He is currently Assist Lecturer in Dept. of Electrical Power Technical Engineering / Electrical Engineering Technical College / Middle Technical University (phone: +9647706227733, email:yasser.atta@eetc.mtu.edu.iq). 